\title{
Optimized location of biomass bales stack for efficient logistics
}

Srinivasagan N. Subhashree ${ }^{a}$, C. Igathinathane ${ }^{\mathrm{a}, \star}$, Ganesh C. Bora ${ }^{\mathrm{a}}$, David Ripplinger ${ }^{\mathrm{b}}$, Leslie Backer ${ }^{\mathrm{a}}$

${ }^{a}$ Department of Agricultural and Biosystems Engineering, North Dakota State University, 1221 Albrecht Boulevard, Fargo, ND 58102, USA

${ }^{b}$ Department of Agribusiness and Applied Economics, North Dakota State University, Richard H. Barry Hall, 811 2nd Ave N. Fargo, ND 58102, USA

\section{Abstract}

Producers often aggregate bales into stacks before transporting these bales to an outlet for consumption or delivery to industrial applications. Efficiency improvement in this infield bale logistics will be beneficial. To address this an $\mathrm{R}$ simulation program involving 4 five methods for field stack location, namely field middle, middle data range, centroid, 5 geometric median, and medoid, as well as origin a direct aggregation method to outlet, 6 were developed. These methods were evaluated against field areas, ranging from 7 0.5-520 ha, for infield bale logistics (aggregation, transport, and total) using Euclidean 8 distances. The simulation used several input field variables, laid out bales based on yield variation, determined optimized bale stack locations of methods, and evaluated distances of aggregation to the stack, transport from the stack to the outlet, and total logistics. The origin method used 1-bale handling tractor for direct aggregation to the outlet, while others formed the bale stacks and transported bales to the outlet using 6-bales/trip equipment. Results indicated for aggregation that geometric median was the best, followed by field middle or centroid, middle data range, medoid, and finally origin. Methods aggregation were about $76 \%$ and transport about $24 \%$ of the total (for $>2$ ha); and total distance were about $65 \%$ of the origin. ANOVA, excluding origin, indicated that all methods were not significantly different $(p<.05)$ for the areas studied. The 'field middle' was recommended as an easy and practical method for locating field stacks. Fitted power models described well $\left(R^{2}>0.99\right)$ all the logistics distances.

\footnotetext{
${ }^{*}$ Corresponding author

Email address: Igathinathane.Cannayen@ndsu.edu (C. Igathinathane )
} 
Keywords: Aggregation, Biomass, Energy, Logistics, Optimization, Transport 


\section{Introduction}

Infield logistics of collecting and moving biomass to a location suitable for further use represents a substantial field operation. Transport of biomass from the point of origin to the point of consumption was conceptually considered as a single logistics operation.

However, a careful examination can reveal that the infield biomass logistics is a

time-consuming operation involving several components. Biomass after harvest is usually made in a compacted form, such as bales and are initially left on the field. In a biomass supply chain, the compacted biomass (e.g., bales) has assumed to be transported to the final destination or grouped at a field edge or collected with self-loading wagons for off-site transport [1]. The aggregated bales are transported to a field outlet, such as a corner or edge of the field before moved to the point of final usage (e.g., biorefinery) or consumption (e.g., cattle feedlot). This logistics operation of land clearance for the next crop is essential for efficient crop production.

Producers often aggregate bales into several stacks in the field before transporting the bales to an outlet. The desire for forming bale stacks in the field is to utilize efficient multiple bale-hauling equipment from the stack to the outlet. Other motivations for the bale stacks formation that will lead to efficient logistics include (i) clearing the field for next crop, (ii) smoother mechanical crop management operations without bales hindrance, (iii) short window between harvest and next planting schedule, and (iv) field conditions may not allow for driving equipment. Thus, given the advantageous role of bale stacks in the infield bale logistics, it will be pertinent to investigate "where" to locate the bale stack so that the logistics will be efficient. Therefore, a study that focuses on the strategic location of the bale stacks, so that the bale aggregation and subsequent transport distances will be minimized, would improve the infield logistics efficiency.

Considering bales as points on a 2D plane, several mathematical grouping methods can be employed to simulate the aggregation of the bales into stacks. These methods of locating bale stack will lead to different locations in the field, based on their algorithm. Using these methods, the optimum bale stack location can be determined that gave the least aggregation or total distances, and the methods can be ranked based on these 
distances. Thus, it was hypothesized that the bale stack location methods will be significantly different from one another, from the viewpoint of infield logistics distances.

Several biomass logistics based studies addressing the biomass logistics in general, supply of biomass to the biorefinery, economics of biomass logistics, and patents related to bale forming and handling machinery were available. Studies involving biomass bale logistics include development of integrated biomass supply and logistics (IBSAL) model and its implementation for feedstock supply chain [2, 3]; development of a MATLAB training tool on the timing and handling and storing round bales with a self-loading wagon [4]; biomass bales transport system based on cotton logistics as model and explored the difference and application [5]; herbaceous biomass bales transportation cost optimization [6]; large biomass modules logistics system to maximize legal highway loads and to minimize feedstock cost based on IBSAL [7]; hybrid genetic algorithm solution for the efficient bale collection routes with a 15- and 35-bales wagon [8]; and simulation of the bales layout mimicking the baler operation, and evaluation of several infield biomass bales aggregation strategies [9].

These studies demonstrate that biomass logistics simulation is a possible way to study the infield logistics and the various components of the supply chain from field to factory including the feedstock supply economics. However, literature on the infield bale logistics involving bale stacks were highly limited. Recently, a bale stack logistics study considered the bale collection logistics effect on the number of subfield bale stacks, locations of bale stack and field outlet, and the number of bales/trip in transport [10]. This study concluded that the best bale stacks location was the subfield middle compared to mid-edges or corners. Given the random layout of bales, it was expected that there could be better locations for the bale stack other than the field middle. Thus, in the present study, further exploration was performed around the field middle to obtain the optimum bale stack location. Several mathematical grouping strategies to obtain different bale stack locations using simulation, and the effect of field variables involved in the infield bale logistics with statistical analysis are proposed to be evaluated in this study.

The specific objectives of the study on the optimized bale stack location are: 
(i) simulate different bale aggregation methods that represent bale stack locations after simulating the layout of bales in the field from various field operation inputs; (ii) evaluate the aggregation, transport, and total infield bale logistics distances of different methods; (iii) determine the effect of area or number of bales on logistics distances and compare methods; and (iv) develop regression models for infield bale logistics distance as a function of area.

\section{Materials and methods}

\subsection{Simulation of bales layout on field}

In this study, the bale logistics simulation, data analysis, and data visualization codes were developed using the statistical analysis software R [11]. 'RStudio,' the integrated development environment that ran R, was used in this study. The bale layout algorithm [9], which mimicked the baling equipment actions of bale formation and layout on the field (Fig.1A), was used in the simulation.

[Fig. 1 about here.]

This algorithm simulated (1) collection of required quantity of biomass that go into the formation of a bale, (2) establishes the "collection length" of the windrow for a bale, (3) lays out the bale and records its coordinates, (4) continues the baling operation after turning at the field edge and keeps accumulating the biomass in the collection length for the next bale, (5) variation of biomass yield through variation factor limit, and random number generation within this limit, and (6) accounted for various input factors, such as field area, length/width ratio, swath of harvester, biomass yield, yield variation, and bale mass. The output of this algorithm will be the total number of bales and their coordinate locations $\left(x_{i}, y_{i}\right)$ on the field. This Java-based algorithm was re-coded in $\mathrm{R}$ to simulate the bales layout on the field, along with simulation of different bale stack location methods.

\subsection{Bales stack formation and transport}

Once the bales layout was generated based on the various inputs to simulate different crops and field sizes, the bales need to be aggregated into field stacks. This bale stack formation 
makes the movement of bales from the stack to the outlet more efficient during transport. This was because the aggregation can handle only a few bales $(\leq 3)$ using a bale loader (tractor attached to bale grapple or spear) compared to wagons/trucks that can handle multiple bales $(\leq 32)$ during transport. In this study, it was assumed that 1 bale was handled in aggregation (e.g., tractor with grapple) and 6 bales in transport (e.g., open trailer) to represent the most basic equipment available in the field. It was also recognized that with the latest equipment, it was possible to handle multiple bales during aggregation (e.g., advanced automatic bale picker) and increase the number of bales $(\geq 6)$ during transport. The lower left corner (origin) of the field was assumed to serve as the outlet. It was also assumed that the distances involved in aggregation and transport were obtained through linear distance connecting the bales and the stack location coordinates, and that between the stack and the outlet, respectively.

\subsection{Process simulation and parameters considered}

The processes involved in determining the efficient location of bale stack from the bales layout along with analysis and visualization in the developed program are presented in the form of a flowchart (Fig. 1B). Several inputs can be varied to accommodate different scenarios to be studied. Areas representing actual field areas in the form of fractional parcels of a "section" of land (259 ha) were considered. Thus, for the purpose of primary analysis, the areas in hectares used in the simulation were $0.41,0.51,1.01,2.02,4.05,8.09$, $16.19,32.38,64.75,129.5$, and 259 ha. Furthermore, several areas at finer intervals ( 2 ha) from 0.5 to 520 ha were used in the statistical analysis. The other parameter considered in the simulation study were: length by width ratio of 1.0; biomass yield per hectare of $5 \mathrm{Mg} / \mathrm{ha}$; harvester swath of $6 \mathrm{~m}$; bale mass of $600 \mathrm{~kg}$; percentage variation of biomass yield of 5\%,7\%, and 10\%; number of bales moved during aggregation/trip was 1; and number of bales moved during transport/trip was 6; and the random seed arbitrarily chosen and used for random number generation in $\mathrm{R}$ that was 2015. Three simulated replications are derived from the biomass yield percentage variation $(5 \%-10 \%)$. 


\subsection{Optimum bale stack location methodologies}

Optimum location is the most favorable spot on the field for stacking the bales so that the total aggregation distance is the least. Many bale grouping/clustering (aggregation) methods based on mathematical techniques of grouping points that are distributed on a two-dimensional plane were considered. These geometrical points used in the grouping were replaced by the layout of bales (Sec. 2.1) and mathematical techniques were applied. Various methods selected for this study were field midpoint, middle data range, centroid, geometric median, and medoid (Fig.2). The hypothesis to be tested was the aggregation or total distances of the methods will be significantly different from one another, and an optimized method will emerge. Direct aggregation of bales to the field outlet was also considered as one of the methods called 'origin.' Details of these six methods are given next.

\subsubsection{Field midpoint}

Field midpoint was the simplest method of all. This represented a constant physical midpoint of the field that was based on field dimensions, and was not affected by the bales layout (Fig. 2). It is easy to locate the midpoint of the field by simply dividing the length and width dimensions by two. Midpoint of a square or rectangular field can also be found out using the midpoints or point of intersection of diagonals. In the simulation, the length and width of the field were calculated from its area and the aspect ratio (length/width). The $x$-axis represents the width of the field and $y$-axis the length. Thus, the field midpoint $x-$ and $y$-coordinates were calculated as:

$$
\begin{aligned}
\text { Length }(\mathrm{m}) & =\sqrt{10000 \times \text { Area }(\text { ha }) \times \text { Length } / \text { Width }} \\
\text { Width }(\mathrm{m}) & =\text { Area/Length } \\
\text { Field midpoint } & =\left(\frac{\text { Width }}{2}, \frac{\text { Length }}{2}\right)
\end{aligned}
$$

\subsubsection{Middle data range of bale coordinates}

Middle data range of bale coordinates is the number that separated the data set's upper half from the lower (Fig.2). From the bale coordinates $\left(x_{i}, y_{i}\right)$, which were stored as 
one-dimensional vectors, the minimum and maximum values of each vector were obtained using the R's 'min()' and ' $\max ()$ ' standard functions. Therefore, the middle value of the bale coordinates was obtained as:

$$
\text { Middle data range }=\left(\frac{\min \left(x_{i}\right)+\max \left(x_{i}\right)}{2}, \frac{\min \left(y_{i}\right)+\max \left(y_{i}\right)}{2}\right)
$$

where $x_{i}$ and $y_{i}$ are the $x$ - and $y$-coordinate vectors of the bales layout, respectively.

\subsubsection{Centroid of bale coordinates}

Centroid of an area is similar to the center of mass, center of gravity of a body, or barycenter, which is the point at which the whole body can be balanced. Centroid of a plane is also known as its 'geometric center.' Similar to the mean, the location of the centroid minimizes the weighted sum of generalized squared Euclidean distances from vector to any points in the space [12]. Applying this concept to a set of points in a plane, the centroid represents the mean position of all the points both in $x$ and $y$ directions (Fig.2). The centroid was determined using R's 'mean()' standard function, and was expressed with usual notations as:

$$
\text { Centroid }=\left(\frac{1}{n} \sum_{i=1}^{n} x_{i}, \frac{1}{n} \sum_{i=1}^{n} y_{i}\right)
$$

where $n$ is the total number of bales in the field.

\subsubsection{Geometric median of bale coordinates}

Geometric median is similar to median, however it is used to compute median for multivariate data and multidimensional spaces. Geometric median of points generated randomly in the X-Y plane is the point from which the sum of Euclidean distances of all the randomly generated points is the least (Fig. 2). Thus, by definition, the geometric median will be the best location for the bale stack. However, it will be useful to statistically compare this method with other simpler methods. There were no explicit formulae for geometric median determination, but iterative process could be used. Theoretically, for a given set of $m$ points $x_{1}, x_{2}, \ldots, x_{m}$ with each $x_{i} \in \mathbb{R}^{n}$, the geometric median was defined as: 


$$
\text { Geometric median }=\underset{y \in \mathbb{R}^{n}}{\arg \min } \sum_{i=1}^{m}\left\|x_{i}-y\right\|_{2}
$$

The 'arg min' of Eq.(4) means the value of the argument $y$ which minimizes the sum. In this case, it was the point $y$ from where the sum of all Euclidean distances to the $x_{i}$ 's was minimum. Using the R package 'pracma,' the geometric median of random points in the two-dimensional space was calculated. This package solved the task by applying an iterative process known as the Weisfield's algorithm [13]. This algorithm defined a set of weights that were inversely proportional to the distances from the current estimate of the samples; and created a new estimate that was the weighted average of the samples according to these weights.

\subsubsection{Medoid of bale coordinates}

Medoid is defined as a representative object of a data set or a cluster with a data set whose average dissimilarity to all the objects in the cluster is minimal. It was more robust because it minimized the sum of dissimilarities instead of the sum of squared Euclidean distances. The medoid is similar to mean or centroid, but it always belongs to a member of a data set

(Fig.2), unlike the other methods studied. Cluster analysis is required to find the medoid of the $\mathrm{X}-\mathrm{Y}$ plane. Clustering is the process of grouping data objects into a set of disjoint classes, called clusters. The objects within a class have high similarity to each other while objects in separate classes are more dissimilar [14].

The medoid was calculated using the algorithm called partitioning around medoids (PAM) with the R package 'cluster' $[15,16]$. For bale aggregation, the medoid was evaluated by setting the number of clusters equal to one. The evaluated medoid coordinates coincide with one of the bale coordinates while in the other methods it may be a point in the field. This means it was easy to mark the medoid on the field, which was nothing but identifying a particular bale (Fig.2).

\subsubsection{Field origin}

Origin is the basic and the most simple method where all bales are directly aggregated to the final outlet. It is also the method where no bale stacks are involved in the bale 
collection. In this method, only bale loader was used in aggregation and bales were directly collected to the outlet; hence, will not have the transport component and the aggregation and total logistics were the same. As the loaders were used in the direct collection of the origin method, and with one bale handling assumption, the logistics distances tend to be the greatest. The origin method can serve as the 'reference method' to compare the other methods.

\subsection{Aggregation to stack location or to outlet}

The aggregation distance determination involved the sum of Euclidean distances of all the bales $\left(x_{i}, y_{i}\right)$ to the point of interest (e.g., methods bale stack location, origin). The point of interest with methods were the different bale stack locations coordinates $\left(x_{m}, y_{m}\right)$, and for the origin method this was the origin $(0,0)$. Therefore, the aggregation distances of the methods and that of origin are:

$$
\begin{aligned}
& \text { Aggregation to stack }=\sum_{i=1}^{n} \sqrt{\left(x_{i}-x_{m}\right)^{2}+\left(y_{i}-y_{m}\right)^{2}} \\
& \text { Aggregation to origin }=\sum_{i=1}^{n} \sqrt{\left(x_{i}-0\right)^{2}+\left(y_{i}-0\right)^{2}}
\end{aligned}
$$

Only the direct single distance connecting the bales location to the point of interest as described through Eqs.(5)-(6) was considered in the analysis. However, for practical operation that involved to-and-fro movement of the equipment, this distance should be doubled.

\subsection{Bale transport to the outlet}

The stacked bales at the optimum locations, based on different methods other than origin, have to be transported to the outlet. The lower-left corner of the field was considered as the outlet in this study, and it coincided with the origin of the field. It was assumed that 6-bales/trip were transported using a bale wagon/truck from the stack location. The total transport distance can be obtained from the constant distance between the bale stack location and the origin times the whole number of 6 bales-trips $\left(N_{6 \_b a l e s}\right)$ to include all the bales of the stack. The transport distances determined were similar to the aggregation 
process (Eqs. (5)-(6)) but they involved simply the bale stack location of the five methods and the outlet $(0,0)$ as:

$$
\text { Transport to outlet }=N_{6 \_ \text {bales }} \times \sqrt{\left(x_{m}-0\right)^{2}+\left(y_{m}-0\right)^{2}}
$$

The collection equipment for transporting round bales includes bale loaders (tractor with grapple; also used in aggregation), and bale wagons/trucks. The different types of bale loaders can handle 1, 2, or 3 bales. Based on the design and capacity, the bale wagons can transport $6,12,26,30,32$ or more bales. There are also other advanced automatic bales pickers that combine the operations of bales loader and wagon, and capacities of 6,10 , and 14 bales [9]. These bale pickers can also be used for aggregation, but their application was not considered in the study.

\subsection{Comparison of bale stack location methods}

The distribution of the bale stack locations from the different methods in the X-Y plane, as it varies with different field areas, is a measure of the variations produced by these methods. One way of evaluating the distribution is by measuring the closed polygonal distance of the stack locations for the five methods. This distance can be evaluated by simply connecting the distances in the order of the methods and termed 'methods distance' (MD) or finding the least distance of a unique polygonal path following the 'traveling salesperson' (TSP) technique [17].

The MD was calculated by adding the distance among various stack locations in the order of the methods used in the analysis, which was arbitrary. The TSP distance was calculated by using the R package 'TSP' [18]. This package deals with Euclidean TSP problem of traversing each point once with the least possible route and solves the problem from the set of points. It is expected that the TSP distance will be smaller than the MD. When the bales locations from different methods converge, as affected by the area of the field, the MD and TSP values will reduce and signify that the methods are not different from one another and vice versa. Therefore, MD and TSP distances serve as measures to quantify the variation of bale stack locations generated by different methods and compare them. 
2.8. Statistical analysis

Apart from simulation model development (Fig. 1B), R [11] was also used for statistical analysis and results visualization. The one-way ANOVA was carried out to test the significant difference between the means of two or more aggregation methods studied. In the ANOVA, the 'origin' method was not considered as it was different and no bale stack was produced in the field before transport to the outlet. Aggregation and total logistics (aggregation + transport) were considered as dependent variables. Statistical significance at $\alpha$ of 0.05 and 0.001 was considered. Based on the results, a practical method will be selected and further analysis, such as correlation and regression model development using R's 'cor( ()' and ' $\operatorname{lm}($ )' commands, respectively. Pearson correlation between area and the logistics distances were evaluated to understand the association of these variables. Suitable regression models were developed with logistics distances as the dependent and field area as the independent variables. The model style was selected by observing the plot diagnostics (e.g., residuals). For visualization and presentation of graphical results, R packages like 'base' and 'ggplot2' were used.

\subsection{Field shape effect on bale logistics}

The bale stack location methods described thus far considered only square and rectangular field shapes (Fig. 3). In U.S. land surveying it is common to delineate parcels of farmlands in terms of square "sections" (259 ha) to enable mechanized agriculture. Therefore, most of the field shapes are square or rectangular, as they were derived usually by divided from these standard sections of land. However, some of the fields tend to be of other shapes as well, such as circular (pivot-irrigated fields) and other polygonal shapes due to exiting boundaries of the land holdings in the U.S. and other parts of the world.

The cultivation practices (e.g., planting, spraying, harvesting) most of the times follow a concentric pattern based on the field shapes (e.g., circular/spiral in pivot-irrigated fields). In such cases the bale layout simulation for square and rectangular fields outlined earlier (Sec. 2.1) will not work and new specific simulation algorithms should be developed, and this may require a future study. However, once the coordinates of bales layout for different 
shapes were obtained, the bale stack locations methods and other other analysis described above (Fig. 1B) will be equally applicable.

\section{Results and discussion}

\subsection{Bale stack location methods distribution}

The hypothesis of different stack location from methods lead to significantly different results can be visualized by plotting their locations among the bales layout. To illustrate the various bale stack locations generated by the methods, a small field of 0.8 ha that made only $5(600 \mathrm{~kg})$ bales was plotted to show the extent of the field (Fig.2).

[Fig. 2 about here.]

[Fig. 3 about here.]

The field midpoint (blue cross) was a fixed location based on the field dimensions while the other methods were based on the bales layout data. It can be seen that the centroid, middle data, and geometric mean methods locations were on the field between the bale locations (green circles), but the medoid coincided with the third bale (from left) location (Fig. 2). Given the layout of these bales the geometric median (brown circle) was the best location to aggregate the bales into a stack. However, the middle data (pink circle) and centroid (blue circle) methods were not much separated from the geometric median. The field outlet (gray diamond), which is the left bottom field corner, is the origin and to where all the bales will be finally transported. It was possible to have the outlet anywhere along the boundary of the field, but the origin was considered in this study, which was equivalent to any other three corners of the field.

To visualize the bale stack locations and their distribution in the field, a 'section' (259 ha) area was considered in the background and four field areas of 32.5, 65, 130, and 259 ha were overlaid (Fig. 3), unlike the zoomed-in view of an exclusive small field (Fig. 2). This plot indicates that all the methods' stack locations converge and methods were indistinguishable irrespective of the areas (32.5 through 259 ha) and the shape (square and rectangular) tested. This cursory observation indicated that the alternative hypothesis, 
which implied that all the methods were statistically similar, was true. However, through rigorous statistical analysis, the correct variation will be revealed.

\subsection{Optimized bale stack location methods results}

Bale stack aggregation methods generated different locations with respect to several field areas considered. These locations produced the associated logistics distances. The logistics distances and the distribution of stack locations evaluated through MD and TSP were determined and presented (Table 1). The origin method had the highest aggregation among all methods and areas, whereas the other methods' aggregation distances were different and they did not vary much from one another because of convergence of locations (Fig.3). As the origin method directly collected all the bales to the outlet during the aggregation, the transport component was not present (Table1). However, the origin method was not as efficient as the other methods, because only single bale was handled each time that increased the logistics distance.

[Table 1 about here.]

Among the other methods, the geometric median was the most efficient with the lowest aggregation distance for all areas, and the reason being the very definition of this method to produce the least grouping distance (Table 1). Similarly, the least efficient (areas $\geq 2.02 \mathrm{ha}$ ) was the medoid with the largest aggregation distance. The reason being the medoid was restrictive and made to coincide with an existing bale location, which might be away from the optimum location in the field. Field middle method closely followed the best geometric median method, while the middle data range and centroid methods also had a similar trend with no clear best.

The transport component was always lower than the aggregation because multiple bales (6-bales/trip) were transported from the bale stack to the outlet (Table 1). The trend of total logistics distance (aggregation + transport) did not follow the similar trend of aggregation, as the transport component was different for each method. For example, the bale stack location closer to the outlet produced a smaller transport distance than stacks away from the outlet. Thus, sometimes even though the geometric median produced the 
lowest aggregation distance, the total distance was always not the best. In general, when the total distance was considered, all the methods had similar values but the origin was always significantly larger compared to the other methods.

\subsection{Effect of field area on the bale stack location methods}

Increased field area obviously produced more bales but in an overall sense, it did not affect the ranking of the methods. It was evident from the area results (Fig.4): (i) all logistics distances increased with area; (ii) origin method's aggregation distances were significantly higher (about twice) than the other methods; (iii) for the rest of the methods, aggregation were similar; (iv) methods' aggregation other than origin were about $76 \%$ and transport about $24 \%$ of the total (for $>2 \mathrm{ha}$ ); (v) the transport distances, however, were about $32 \%$ of aggregation or $24 \%$ of total; (vi) with the multiple 6-bales transports, the total distance of the methods were still significantly smaller (about 65\%) than the origin; and (vii) no clear distinction was observed in the total distance among the methods other than the origin. Overall, since a similar pattern emerged for all logistics distances (Fig.4), it can be concluded that field areas or the number of bales did not affect the ranking of the methods. This also indicated that any method other than the origin can be equally used.

\section{[Fig. 4 about here.]}

\subsection{Distribution of bale stack location methods}

The distribution of the methods (excluding origin) were studied through MD and TSP distances (Table 1). The TSP distances were always smaller than the MD. Both these values were quite small (MD $\leq 0.114 \mathrm{~km}$ and $\mathrm{TSP} \leq 0.1 \mathrm{~km})$ compared to the total distance $(0.13-4927 \mathrm{~km})$ for the area range studied $(0.41-517 \mathrm{ha})$. These low values of the methods distribution (MD and TSP) indicated that there was no variation in the layout distribution among the methods, irrespective of the area or number of bales, as earlier observed (Fig.3).

A plot of these distributions with a series of areas from 0.5 to 520 ha at 2 ha intervals helped further to explore any converging trend of these distributions (Fig.5) . Along with MD and TSP, the difference between the two allowed for easy comparison. The TSP was most often smaller than MD, but the difference was very small in most areas as well. The 
pattern of these distribution parameters did not show any convergence with the increase in area. These variations, however, changed with different random number seeds (e.g., 2016 and 2017; Fig.5). This result showed that there was no particular area where the methods distances converge. The emergence of random variation or no trend again confirms the non-convergence of the methods distribution. Thus, any method other than origin can serve well and this observation is applicable to any area.

[Fig. 5 about here.]

\subsection{Statistical analysis results}

The analysis was conducted using the one-way ANOVA, where the methods (excluding origin) were tested for their significant difference based on field areas ( 0.5 to 520 ha at 2 ha intervals) and biomass yield variations $(5 \%, 7 \%$, and $10 \%)$ produced the replications. The ANOVA results are given in the form of a figure showing the significant difference at p-levels of 0.05 and 0.01 for aggregation and total logistics distances (Fig.6A).

[Fig. 6 about here.]

The results showed that several areas $(\leq 11.8 \%)$ produced significant differences among the methods, while the predominant area ranges were not for aggregation and total logistics (Fig. 6A). Of the 262 levels of areas studied, 7 (2.7\%) and 4 (1.5\%) areas were significantly different for aggregation and 31 (11.8\%) and $12(4.6 \%)$ for total logistics at $p$-levels of 0.05 and 0.01 , respectively. No single area cutoff was found that divided the methods to be significant. The results were obtained by a random seed of 2015 , and the results patterns were expected to be different with other seed values as observed earlier (Fig. 6A).

\subsection{Comparison of geometric median and field middle methods}

A further analysis was performed to exclusively compare the best geometric median (GM) and simplest field middle (FM) methods closely considering 262 areas continuously from 0.5 to 520 ha at an interval of 2 ha for windrow variations of $5 \%-10 \%$ (Table 2). The actual 
values of both methods were close showing only a deviation of $\geq \pm 0.2 \%$ GM from FM for areas $\leq 4$ ha with aggregation and $\leq 34$ ha with total logistics distances, and no deviations with larger areas (data not shown). By principle, the GM should yield the lowest aggregation distances. It was found that GM was exclusively lower than FM for $\leq 85.5 \%$, and coincides with FM for about $14 \%-21 \%$ of cases, which resulted in $\leq 99.6 \%$ cases for $\mathrm{GM}<\mathrm{FM}$

\section{[Table 2 about here.]}

With the total logistics distances, GM was equally lower than FM in a reduced range of $44 \%-58 \%$, but will be greater than FM for $41 \%-56 \%$ (Table2). Even though in aggregation GM was the most efficient, in total distance either GM or FM were equally good, because the transport distance that affects the total logistics will be greater if the GM location was away from the outlet compared to FM. Thus, it appears that both GM and FM were located towards the outlet equally leading to reduced total logistics distances. Furthermore, the actual deviations between GM and FM $(\geq 0.2 \%)$ were very low, as the number of cases was $\leq 1.5 \%$ for aggregation and $\leq 3.8 \%$ for total logistics distances. These deviations were observed only in the lower ranges of field areas $\leq 4$ ha and $\leq 34$ ha for aggregation and total logistics, respectively. In addition, a $1 \%$ deviation or more was observed only with 1 ha field area or less for both distances. Based on these results and considering the simplicity, the FM can be readily recommended as the method for bale stack location, as the FM was easy to delineate and practical to use.

The differences in strategies between the recent [10] and the present studies lies in the locating the field stacks, namely the former used directly the mid-edges along the boundaries of the field, field corners, and field middle, but the latter used the bale layout coordinates to arrive at several methods around the field middle to determine the optimum location, but rest of the evaluation of bale logistics distances are the same. The previous study [10] indicated that formation of stacks in the middle of the subfield compared to mid-edges or corners significantly reduced the all logistics (aggregation, transport, and total) distances. While the present work supporting the previous findings, it further indicates that unless the subfield areas are $\leq 1$ ha the FM is the best location for the bale 
stacks. Based on the results, for smaller field areas ( $\leq 1 \mathrm{ha}$ ), GM is the best location for aggregation, and the total logistics should be decided according to the nearness of GM or FM with respect to the outlet.

\subsection{Regression models of logistics distances}

Even though the aggregation distances of the FM were larger, especially with smaller areas $(\leq 1.01 \mathrm{ha})$ with fewer bales $(\leq 8)$, the total distance was comparable to the other methods (Table 1). For areas $\geq 2.02$ ha, the difference of the total logistics distance of FM ranged only from $-0.34 \%$ to $0.18 \%$ with reference to the best method in each area. Exclusive comparison between GM and FM (Table2) also supports this observation. Similar differences were expected in the other intermediate areas comparing other methods, but were not tested. Therefore, for practical use and simplicity, the FM method was selected for further correlation analysis and regression model development. The logistics distances (aggregation, transport, and total) with field areas incorporating the biomass yield variation ( 0.5 to 520 ha $\rightarrow 262$ areas; 3 yield variations of $5 \%, 7 \%$, and 10\%; 786 data points) were well correlated and the Pearson's correlation coefficients are $\geq 0.989$.

The basic plot of area versus logistics distances showed a power variation. Therefore, the simplest linear model was found inadequate and the regression diagnostics of residuals revealed a systematic pattern (parabolic). However, with logarithmic transformation both for area and logistic distances, the linear variations were observed and power models were developed (Fig.6B). The following models of logistics distances of the FM method had excellent fits $\left(R^{2}>0.99\right)$ :

$$
\begin{aligned}
\text { Aggregation }(\mathrm{km}) & =0.325 \times \text { Area }(\mathrm{ha})^{1.497} & & \left(R^{2}>0.99\right) \\
\operatorname{Transport}(\mathrm{km}) & =0.108 \times \text { Area }(\mathrm{ha})^{1.483} & & \left(R^{2}>0.99\right) \\
\operatorname{Total}(\mathrm{km}) & =0.434 \times \text { Area }(\mathrm{ha})^{1.493} & & \left(R^{2}>0.99\right)
\end{aligned}
$$

Residuals of these models did not show any systematic variation and the models were acceptable. These models are easy to apply and estimate the logistics distances from the areas. Because the difference in the logistics distance of the other methods was coinciding, 
a similar power model variations were expected as well with other methods.

The bale stack location methods can be extended to multiple bale stacks, wherein the large field can be conceptually divided into smaller subfield units and the bales stacks were made at each subfield as reported earlier [10]. Then the bales of the multiple stacks can be transported as usual to the outlet. As the harvest usually takes place for the entire field in a single stretch, the bale formation can be for the whole field, but the stacks formation can be for the identified subfields. The outlets can also be located anywhere along the field boundary (e.g., middle of width, middle of length) or even at the center or other locations based on farmstead location, especially when existing roads/pathways were available. With such alternate locations for the outlet, all the logistics distances will be different and smaller, as the corner outlet was the farthest point from the field middle. Future research work should address these multiple bale stacks, locations of various outlets, other field shapes, use of automatic bale-picker for aggregation, the economics involved, and their effect on the various bale stack location methods in the infield bale logistics operations.

\section{Conclusions}

Five bale stack location methods, namely field middle, middle data range, centroid, geometric median, and medoid, as well as a direct bale aggregation method to the outlet were simulated and compared using a developed R-program. The geometric median followed by field middle, middle data range, medoid, and finally origin were the best method for bale stack location. Methods' aggregation were about $76 \%$ and transport about $24 \%$ of the total (for $>2 \mathrm{ha}$ ); and total distance were about $65 \%$ of the 'origin.' Distribution of the five bale stacking methods evaluated through 'grouped methods distance' and 'travel salesperson' did not follow any pattern with field areas, which indicated no convergence and meant any method can be applied equally. Even though ANOVA indicated that several areas $(\leq 11.8 \%)$ produced significant differences among the methods $(p<0.05)$, predominant area ranges (0.5-520 ha) were not different for aggregation and total logistics excluding origin for the 6-bales/trip transport. Only $1 \%$ deviation or more was observed with field area $\leq 1$ ha for both aggregation and total logistics distances, when geometric 
median and field middle methods were exclusively compared. Therefore, the 'field middle' was recommended as an easier and practical method because its location can be readily obtained. All the logistics distances of field middle method with 6-bales/trip were well described by power models $\left(R^{2}>0.99\right)$. These logistics models can be used to predict the aggregation, transport, and total distances from the field area of interest (0.5-520 ha).

\section{Acknowledgements}

This work was supported in part by the USDA National Institute of Food and Agriculture, Hatch

Project: ND01472, Accession number: 229896.

[1] R.D. Perlack, A.F. Turhollow, Assessment of options for the collection, handling, and transport of corn stover, Oak Ridge National Laboratory, Oak Ridge, Tennessee, ORNL/TM-2002/44, 2002.

[2] S. Sokhansanj, A. Kumar, A.F. Turhollow, Development and implementation of integrated biomass supply analysis and logistics model (IBSAL), Biomass Bioenergy 30 (2006) 838-847.

[3] A. Kumar, S. Sokhansanj, Switchgrass (Panicum vigratum, L.) delivery to a biorefinery using integrated biomass supply analysis and logistics (IBSAL) model, Bioresour. Technol. 98 (2007) 1033-1044.

[4] R.D. Grisso, J.S. Cundiff, D.H. Vaughan, Investigating machinery management parameters with computer tools, ASABE Paper No. 071030. St. Joseph, MI: ASABE, 2007.

[5] P.P. Ravula, R.D. Grisso, J.S. Cundiff, Cotton logistics as a model for a biomass transportation system, Biomass Bioenergy 32 (2008) 314-325.

[6] J.S. Cundiff, R.D. Grisso, Containerized handling to minimize hauling cost of herbaceous biomass, Biomass Bioenergy 32 (2008) 308-313.

[7] H. An, S.W. Searcy, Economic and energy evaluation of a logistics system based on biomass modules, Biomass Bioenergy 46 (2012) 190-202. 
[8] C. Gracia, B. Diezma-Iglesias, P. Barreiro, A hybrid genetic algorithm for route optimization in the bale collecting problem, Spanish J. Agric. Res. 11 (2013) $603-614$.

[9] C. Igathinathane, D. Archer, C. Gustafson, M. Schmer, J. Hendrickson, S. Kronberg, D. Keshwani, L. Backer, K. Hellevang, T. Faller, Biomass round bales infield aggregation logistics scenarios, Biomass Bioenergy 66 (2014) 12-26.

[10] C. Igathinathane, J.S. Tumuluru, D. Keshwani, M. Schmer, D. Archer, M. Liebig, J. Halvorson, J. Hendrickson, S. Kronberg, Biomass bale stack and field outlet locations assessment for efficient infield logistics, Biomass Bioenergy 91 (2016) $217-226$.

[11] R Core Team, R: A Language and Environment for Statistical Computing, R Foundation for Statistical Computing, Vienna, Austria, 2015. URL: https://www.R-project.org/.

[12] H. e Abdi, Notations and definition (2009).

[13] E. Weiszfeld, F. Plastria, On the point for which the sum of the distances to $\mathrm{n}$ given points is minimum, Ann. Oper. Res. 167 (2009) 7-41.

[14] D. Jiang, C. Tang, A. Zhang, Cluster analysis for gene expression data: A survey, Knowledge and Data Engineering, IEEE Trans. Knowl. Data Eng. 16 (2004) $1370-1386$.

[15] M. Maechler, P. Rousseeuw, A. Struyf, M. Hubert, K. Hornik, Cluster: Cluster Analysis Basics and Extensions, 2015. R package version 2.0.3.

[16] A.P. Reynolds, G. Richards, B. de la Iglesia, V.J. Rayward-Smith, Clustering rules: a comparison of partitioning and hierarchical clustering algorithms, J. Math. Modell. Algorithms 5 (2006) 475-504.

[17] M. Hahsler, K. Hornik, TSP - Infrastructure for the traveling salesperson problem, Journal of Statistical Software 23 (2007) 1-21. 
544 [18] M. Hahsler, K. Hornik, TSP: Traveling Salesperson Problem (TSP), 2015. URL:

545 http://CRAN.R-project. org/package=TSP, R package version 1.1-3. 
List of Tables

547 1 Methods of optimum bale stack locations and their logistics distances and methods combined distances. . . . . . . . . . . . . . . . . .

2 Comparison of field middle and geometric median logistics among various 
Table 1

Methods of optimum bale stack locations and their logistics distances and methods combined distances.

\begin{tabular}{|c|c|c|c|c|c|c|c|}
\hline $\begin{array}{l}\text { Area (ha) } \\
{[\mathrm{ac}]}\end{array}$ & $\begin{array}{l}\text { Number } \\
\text { of bales }\end{array}$ & Methods & $\begin{array}{l}\text { Aggregation } \\
(\mathrm{km})\end{array}$ & $\begin{array}{l}\text { Transport } \\
(\mathrm{km})\end{array}$ & $\begin{array}{l}\text { Total } \\
(\mathrm{km})\end{array}$ & $\begin{array}{l}\mathrm{MD}^{\dagger} \\
(\mathrm{km})\end{array}$ & $\begin{array}{l}\mathrm{TSP}^{\ddagger} \\
(\mathrm{km}) \\
\end{array}$ \\
\hline $\begin{array}{l}0.41 \\
{[1]}\end{array}$ & 3 & $\begin{array}{l}\text { Origin } \\
\text { Field middle } \\
\text { Middle data range } \\
\text { Centroid } \\
\text { Geometric median } \\
\text { Medoid }\end{array}$ & $\begin{array}{l}0.196 \\
0.085 \\
0.070 \\
0.068 \\
0.065 \\
0.068\end{array}$ & $\begin{array}{l}0 \\
0.045 \\
0.061 \\
0.062 \\
0.064 \\
0.075\end{array}$ & $\begin{array}{l}0.196 \\
0.130 \\
0.131 \\
0.130 \\
0.129 \\
0.143\end{array}$ & 0.070 & 0.045 \\
\hline $\begin{array}{l}0.51 \\
{[1.25]}\end{array}$ & 4 & $\begin{array}{l}\text { Origin } \\
\text { Field middle } \\
\text { Middle data range } \\
\text { Centroid } \\
\text { Geometric median } \\
\text { Medoid }\end{array}$ & $\begin{array}{l}0.240 \\
0.107 \\
0.108 \\
0.102 \\
0.099 \\
0.101\end{array}$ & $\begin{array}{l}0 \\
0.050 \\
0.052 \\
0.057 \\
0.067 \\
0.072\end{array}$ & $\begin{array}{l}0.240 \\
0.158 \\
0.160 \\
0.159 \\
0.166 \\
0.172\end{array}$ & 0.054 & 0.048 \\
\hline $\begin{array}{l}1.01 \\
{[2.5]}\end{array}$ & 8 & $\begin{array}{l}\text { Origin } \\
\text { Field middle } \\
\text { Middle data range } \\
\text { Centroid } \\
\text { Geometric median } \\
\text { Medoid }\end{array}$ & $\begin{array}{l}0.462 \\
0.404 \\
0.205 \\
0.206 \\
0.205 \\
0.206\end{array}$ & $\begin{array}{l}0 \\
0.142 \\
0.109 \\
0.114 \\
0.109 \\
0.103\end{array}$ & $\begin{array}{l}0.462 \\
0.546 \\
0.315 \\
0.320 \\
0.314 \\
0.308\end{array}$ & 0.095 & 0.051 \\
\hline $\begin{array}{l}2.02 \\
{[5]}\end{array}$ & 18 & $\begin{array}{l}\text { Origin } \\
\text { Field middle } \\
\text { Middle data range } \\
\text { Centroid } \\
\text { Geometric median } \\
\text { Medoid }\end{array}$ & $\begin{array}{l}1.80 \\
0.87 \\
0.87 \\
0.86 \\
0.86 \\
0.89\end{array}$ & $\begin{array}{l}0 \\
0.30 \\
0.30 \\
0.31 \\
0.31 \\
0.35\end{array}$ & $\begin{array}{l}1.80 \\
1.17 \\
1.17 \\
1.17 \\
1.18 \\
1.24\end{array}$ & 0.054 & 0.034 \\
\hline $\begin{array}{l}4.05 \\
{[10]}\end{array}$ & 33 & $\begin{array}{l}\text { Origin } \\
\text { Field middle } \\
\text { Middle data range } \\
\text { Centroid } \\
\text { Geometric median } \\
\text { Medoid }\end{array}$ & $\begin{array}{l}5.26 \\
3.11 \\
3.11 \\
3.11 \\
3.11 \\
3.45\end{array}$ & $\begin{array}{l}0 \\
0.85 \\
0.86 \\
0.86 \\
0.88 \\
1.09\end{array}$ & $\begin{array}{l}5.26 \\
3.96 \\
3.97 \\
3.97 \\
3.99 \\
4.53\end{array}$ & 0.144 & 0.100 \\
\hline $\begin{array}{l}8.09 \\
{[20]}\end{array}$ & 67 & $\begin{array}{l}\text { Origin } \\
\text { Field middle } \\
\text { Middle data range } \\
\text { Centroid } \\
\text { Geometric median } \\
\text { Medoid }\end{array}$ & $\begin{array}{l}14.63 \\
7.29 \\
7.29 \\
7.29 \\
7.28 \\
7.29\end{array}$ & $\begin{array}{l}0 \\
2.41 \\
2.43 \\
2.43 \\
2.45 \\
2.41\end{array}$ & $\begin{array}{l}14.63 \\
9.71 \\
9.72 \\
9.72 \\
9.73 \\
9.70\end{array}$ & 0.024 & 0.021 \\
\hline $\begin{array}{l}16.19 \\
{[40]}\end{array}$ & 133 & $\begin{array}{l}\text { Origin } \\
\text { Field middle } \\
\text { Middle data range } \\
\text { Centroid } \\
\text { Geometric median } \\
\text { Medoid }\end{array}$ & $\begin{array}{l}40.67 \\
20.28 \\
20.29 \\
20.28 \\
20.28 \\
20.52\end{array}$ & $\begin{array}{l}0 \\
6.54 \\
6.61 \\
6.51 \\
6.58 \\
6.88\end{array}$ & $\begin{array}{l}40.67 \\
26.82 \\
26.89 \\
26.79 \\
26.86 \\
27.39\end{array}$ & 0.074 & 0.072 \\
\hline $\begin{array}{l}32.38 \\
{[80]}\end{array}$ & 270 & $\begin{array}{l}\text { Origin } \\
\text { Field middle } \\
\text { Middle data range } \\
\text { Centroid } \\
\text { Geometric median } \\
\text { Medoid }\end{array}$ & $\begin{array}{l}117.89 \\
58.92 \\
58.92 \\
58.92 \\
58.92 \\
59.18\end{array}$ & $\begin{array}{l}0 \\
18.11 \\
18.22 \\
18.16 \\
18.19 \\
18.11\end{array}$ & $\begin{array}{l}117.89 \\
77.03 \\
77.14 \\
77.08 \\
77.11 \\
77.29\end{array}$ & 0.060 & 0.052 \\
\hline $\begin{array}{l}64.75 \\
{[160]}\end{array}$ & 540 & $\begin{array}{l}\text { Origin } \\
\text { Field middle } \\
\text { Middle data range } \\
\text { Centroid } \\
\text { Geometric median } \\
\text { Medoid }\end{array}$ & $\begin{array}{l}333.12 \\
166.52 \\
166.53 \\
166.52 \\
166.52 \\
166.81\end{array}$ & $\begin{array}{l}0 \\
51.21 \\
51.41 \\
51.26 \\
51.30 \\
51.23\end{array}$ & $\begin{array}{l}333.12 \\
217.73 \\
217.93 \\
217.78 \\
217.82 \\
218.05\end{array}$ & 0.049 & 0.043 \\
\hline $\begin{array}{l}129.5 \\
{[320]}\end{array}$ & 1082 & $\begin{array}{l}\text { Origin } \\
\text { Field middle } \\
\text { Middle data range } \\
\text { Centroid } \\
\text { Geometric median } \\
\text { Medoid }\end{array}$ & $\begin{array}{l}943.38 \\
470.83 \\
470.83 \\
470.83 \\
470.83 \\
471.26\end{array}$ & $\begin{array}{l}0 \\
145.65 \\
145.79 \\
145.91 \\
145.83 \\
148.53\end{array}$ & $\begin{array}{l}943.38 \\
616.48 \\
616.62 \\
616.74 \\
616.66 \\
619.79\end{array}$ & 0.051 & 0.029 \\
\hline $\begin{array}{l}259 \\
{[640]}\end{array}$ & 2163 & $\begin{array}{l}\text { Origin } \\
\text { Field middle } \\
\text { Middle data range } \\
\text { Centroid } \\
\text { Geometric median } \\
\text { Medoid }\end{array}$ & $\begin{array}{l}2665.34 \\
1331.20 \\
1331.21 \\
1331.19 \\
1331.19 \\
1331.32\end{array}$ & $\begin{array}{l}0 \\
410.81 \\
411.45 \\
411.07 \\
411.25 \\
407.51\end{array}$ & $\begin{array}{l}2665.34 \\
1742.01 \\
1742.66 \\
1742.27 \\
1742.44 \\
1738.83\end{array}$ & 0.028 & 0.027 \\
\hline $\begin{array}{l}517 \\
{[1280]}\end{array}$ & 4324 & $\begin{array}{l}\text { Origin } \\
\text { Field middle } \\
\text { Middle data range } \\
\text { Centroid } \\
\text { Geometric median } \\
\text { Medoid }\end{array}$ & $\begin{array}{l}7531.35 \\
3765.75 \\
3765.77 \\
3765.75 \\
3765.75 \\
3765.86\end{array}$ & $\begin{array}{l}0 \\
1160.34 \\
1160.95 \\
1160.51 \\
1160.39 \\
1159.71\end{array}$ & $\begin{array}{l}7531.35 \\
4926.09 \\
4926.72 \\
4926.26 \\
4926.15 \\
4925.57\end{array}$ & 0.022 & 0.020 \\
\hline
\end{tabular}

$\dagger \mathrm{MD}$ - Methods distance i.e. total polygonal distance of all methods taken in the selected order; $\ddagger$ TSM - Traveling sales man distance i.e. total polygonal distance of all methods following traveling sales man technique; Origin was the outlet location where bales were finally transported; and medoid was the aggregation method where it coincided on one of the field stacks but other methods may not. 


\section{Table 2}

Comparison of field middle and geometric median logistics among various field areas from 0.5 to 520 ha.

\begin{tabular}{|c|c|c|c|c|c|c|}
\hline \multirow{2}{*}{$\begin{array}{l}\text { Windrow } \\
\text { variation }(\%)\end{array}$} & \multicolumn{3}{|c|}{ Aggregation (\% cases) } & \multicolumn{3}{|c|}{ Total logistics (\% cases) } \\
\hline & $\mathrm{GM}<\mathrm{FM}$ & $\mathrm{GM} \leq \mathrm{FM}$ & $\begin{array}{l}\text { Abs.GM:FM } \\
\text { Dev. } \geq 0.2 \%^{\dagger}\end{array}$ & $\mathrm{GM}<\mathrm{FM}$ & $\mathrm{GM}>\mathrm{FM}$ & $\begin{array}{l}\text { Abs.GM:FM } \\
\text { Dev. } \geq 0.2 \%^{\dagger}\end{array}$ \\
\hline $\begin{array}{l}5 \\
7 \\
10\end{array}$ & $\begin{array}{l}78.2 \\
81.7 \\
85.5\end{array}$ & $\begin{array}{l}99.2 \\
99.6 \\
99.2\end{array}$ & $\begin{array}{l}1.5 \\
1.1 \\
0.8\end{array}$ & $\begin{array}{l}44.3 \\
46.6 \\
58.4\end{array}$ & $\begin{array}{l}55.7 \\
53.4 \\
41.2\end{array}$ & $\begin{array}{l}3.4 \\
3.8 \\
3.8\end{array}$ \\
\hline
\end{tabular}

$\dagger$ - Percent of cases having absolute deviation of GM with respect to FM $\geq 0.2 \%$; GM - Geometric median; FM - Field middle. The total number of field areas considered continuously spaced at 2 ha $=262$. 


\section{List of Figures}

1 (A) Formed bales on the field ready to be aggregated into bale stacks, and (B) flow diagram of process simulation of bale stack aggregation methods, infield transport logistics, and statistical analysis. . . . . . . . . . . . . . 27

2 Bale aggregation methods studied are illustrated with a small field area (0.8 ha) with a limited number of bales $(\mathrm{n}=5) \ldots \ldots \ldots \ldots$

3 Bales layout and bale aggregation methods location for different field areas overlaid in a section area of land. Simulation data: biomass yield/ha = $5 \mathrm{Mg}$; bale mass $=600 \mathrm{~kg}$; harvester swath $=6 \mathrm{~m}$; aspect ratio $=1.0$ and 0.5 ; random variation in biomass yield $=10 \%$; and random number seed

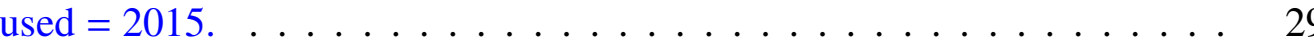

4 Aggregation, transport, and total logistics distances of different aggregation methods studied as presented in Fig. 3. The number of bales hauled per transport trip was six. . . . . . . . . . . . . . . . . 30

5 Variation of grouped methods except origin and traveling sales person distance, its difference, and the effect of random number generation seeds. . 31

6 (A) ANOVA of aggregation and total logistics as influenced by field area. Field parameters used were similar to Fig. 3. The presence of a bar represents a significant difference among studied methods but origin, at that field area and level of significance ( $p$-value). The total refers to the sum of aggregation and transport with 6-bales/trip. (B) Fitted power models for logistics distances for the selected field middle method. . . . . . . . . . . . 32 

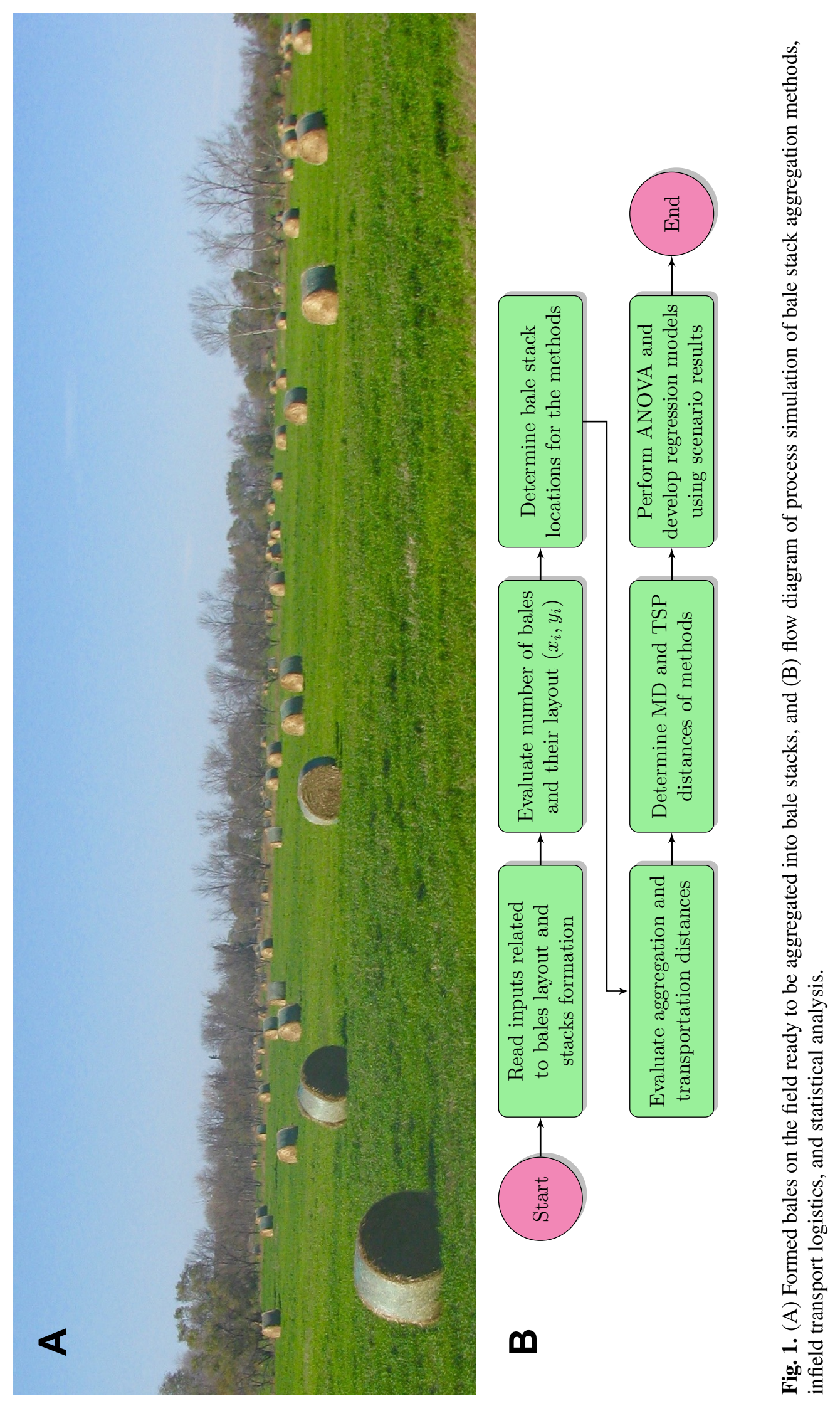


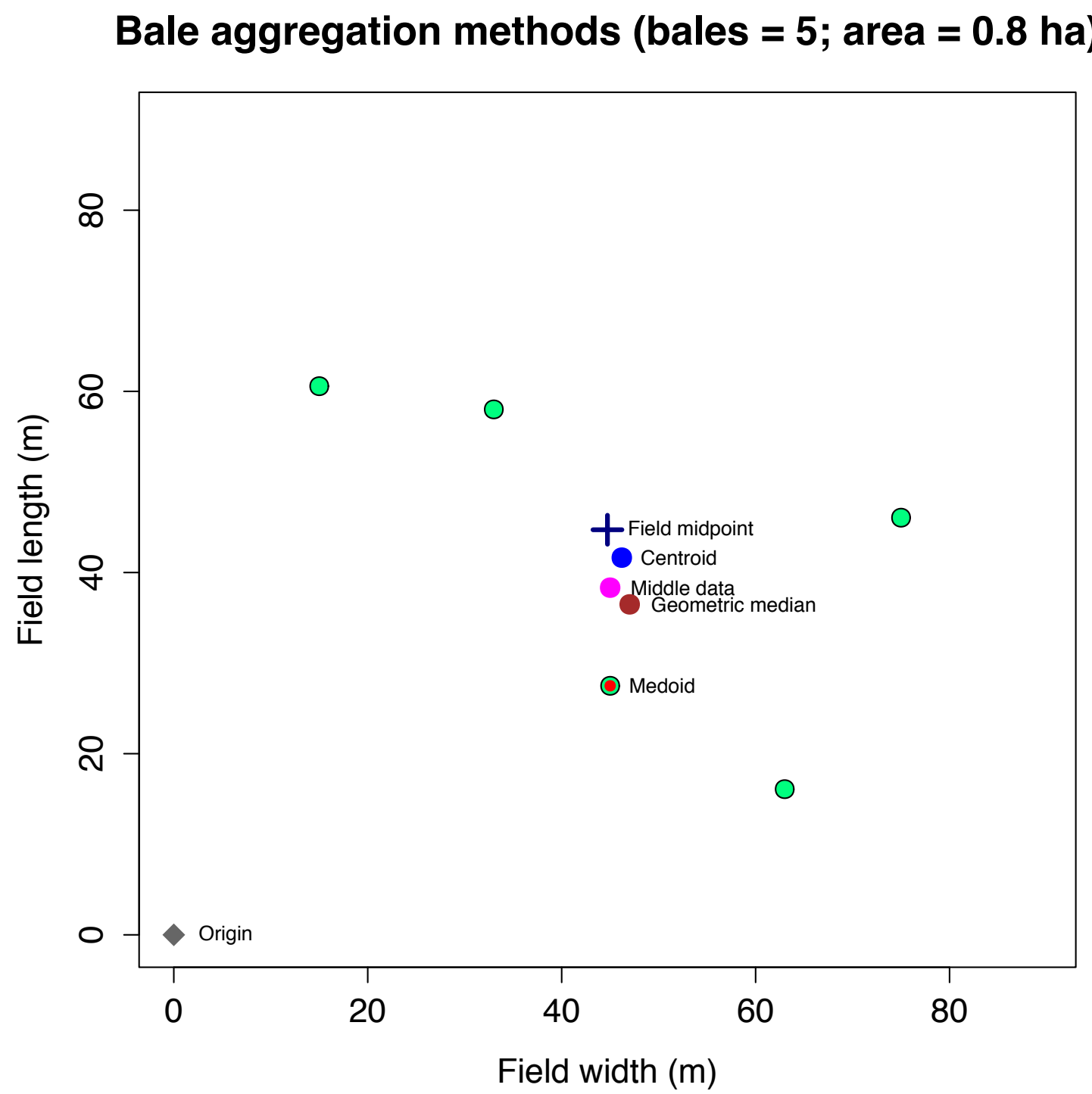

Fig. 2. Bale aggregation methods studied are illustrated with a small field area ( $0.8 \mathrm{ha})$ with a limited number of bales $(n=5)$. 

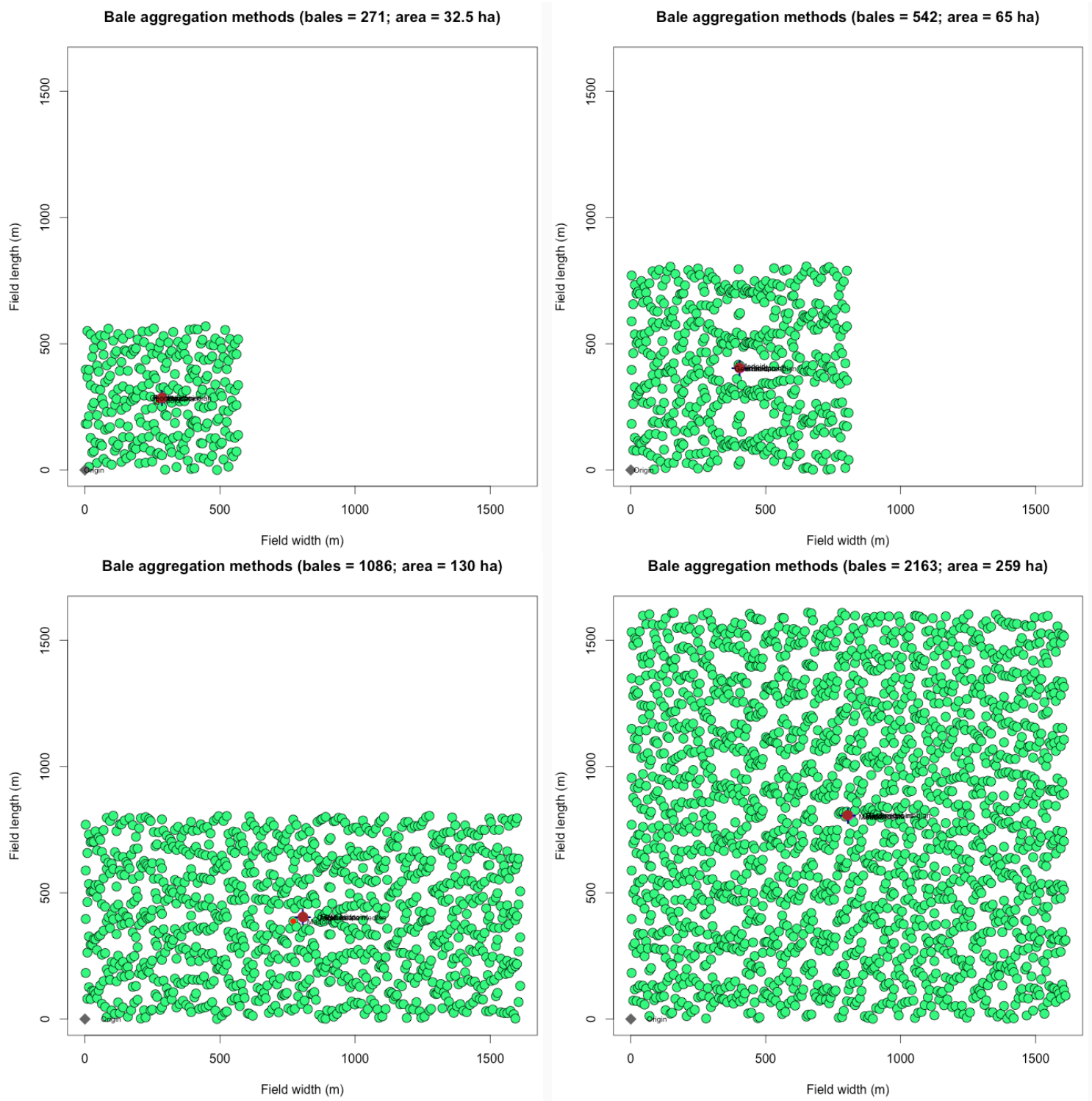

Fig. 3. Bales layout and bale aggregation methods location for different field areas overlaid in a section area of land. Simulation data: biomass yield $/ \mathrm{ha}=5 \mathrm{Mg}$; bale mass $=600 \mathrm{~kg}$; harvester swath $=6 \mathrm{~m}$; aspect ratio $=$ 1.0 and 0.5 ; random variation in biomass yield $=10 \%$; and random number seed used $=2015$. 


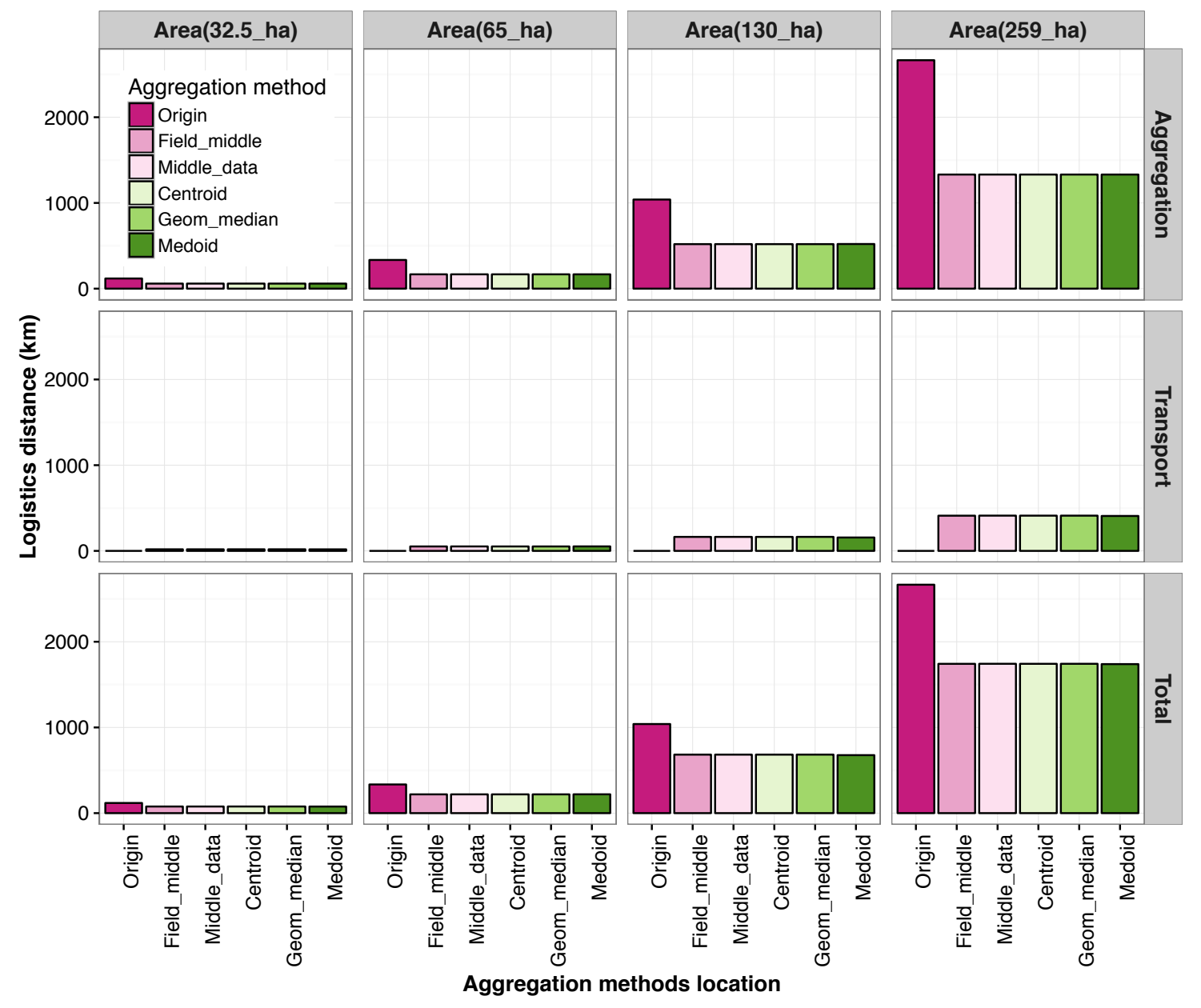

Fig. 4. Aggregation, transport, and total logistics distances of different aggregation methods studied as presented in Fig. 3. The number of bales hauled per transport trip was six. 


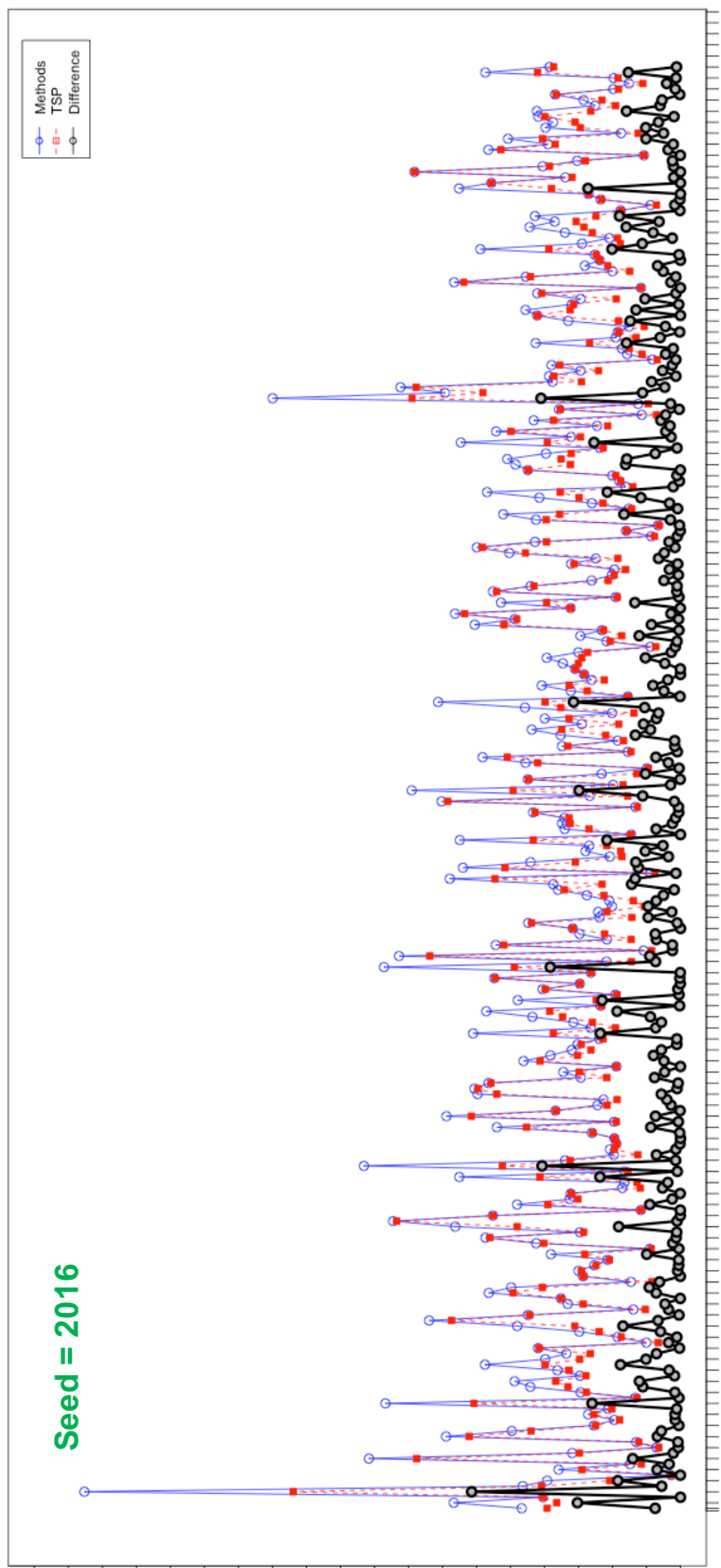

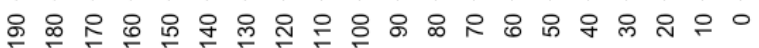
(u) әэuełs!p pədnoı6 spouıәW

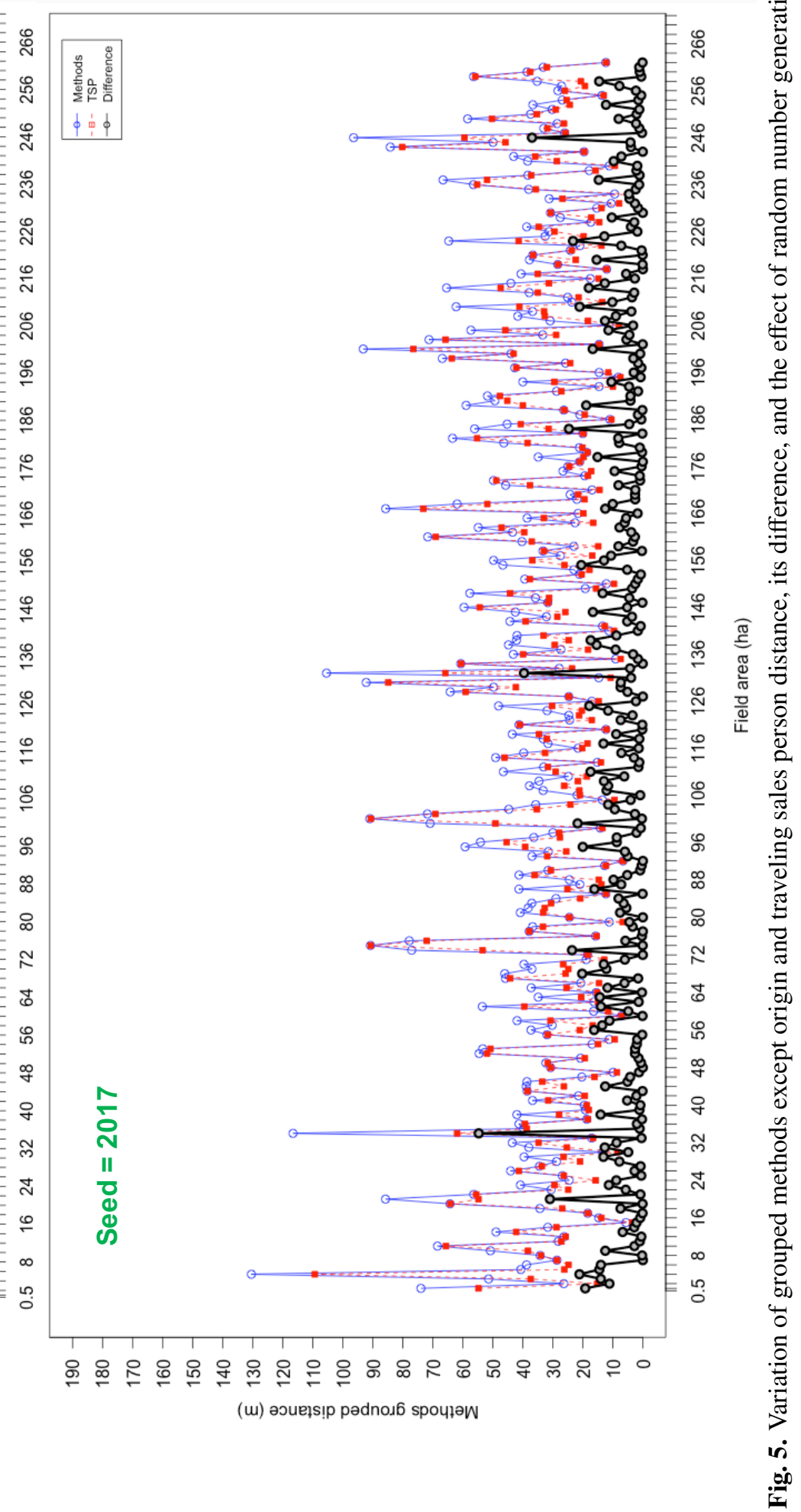



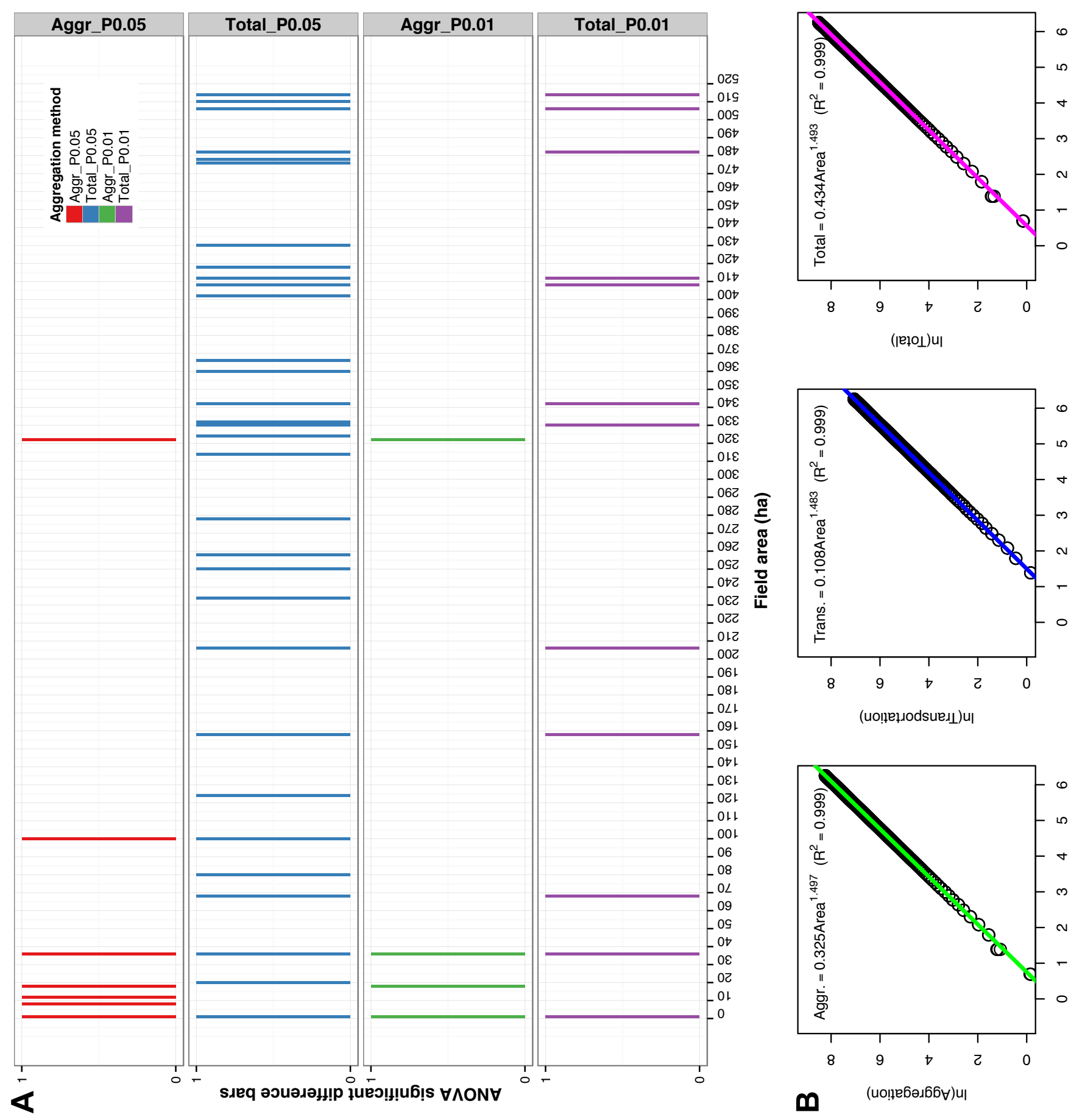

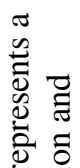

ส

ล

पे

¿

屯ै

造

E

त)

$\therefore \frac{0}{2}$

江

종

초

छ

न

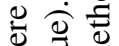

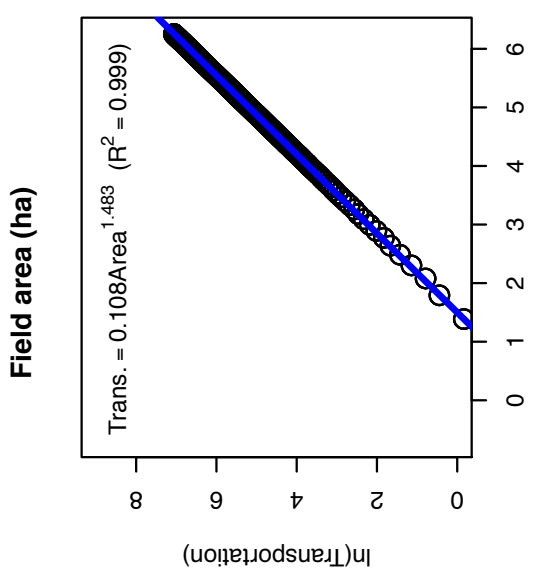

3 त

胥主

\&

ప



점

त $0 . \overline{0}$ ¿ 0

ชं ฮِ

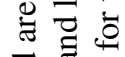

궁

늘

스유.

륭 뭉

ฮี

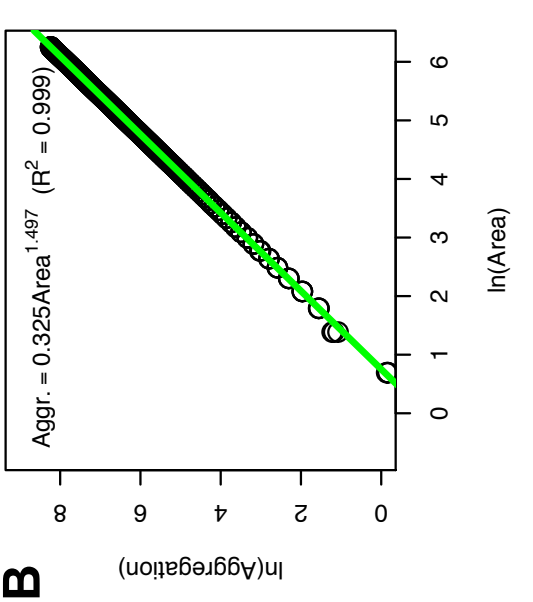

충

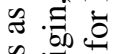

记

吾

이 (口)

픙

웡

ส

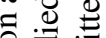

음

萬

को

政

4 \&

¿

乙氜

不

« స్ㅠ

느 की 
Graphical Abstract

\section{Graphical abstract}
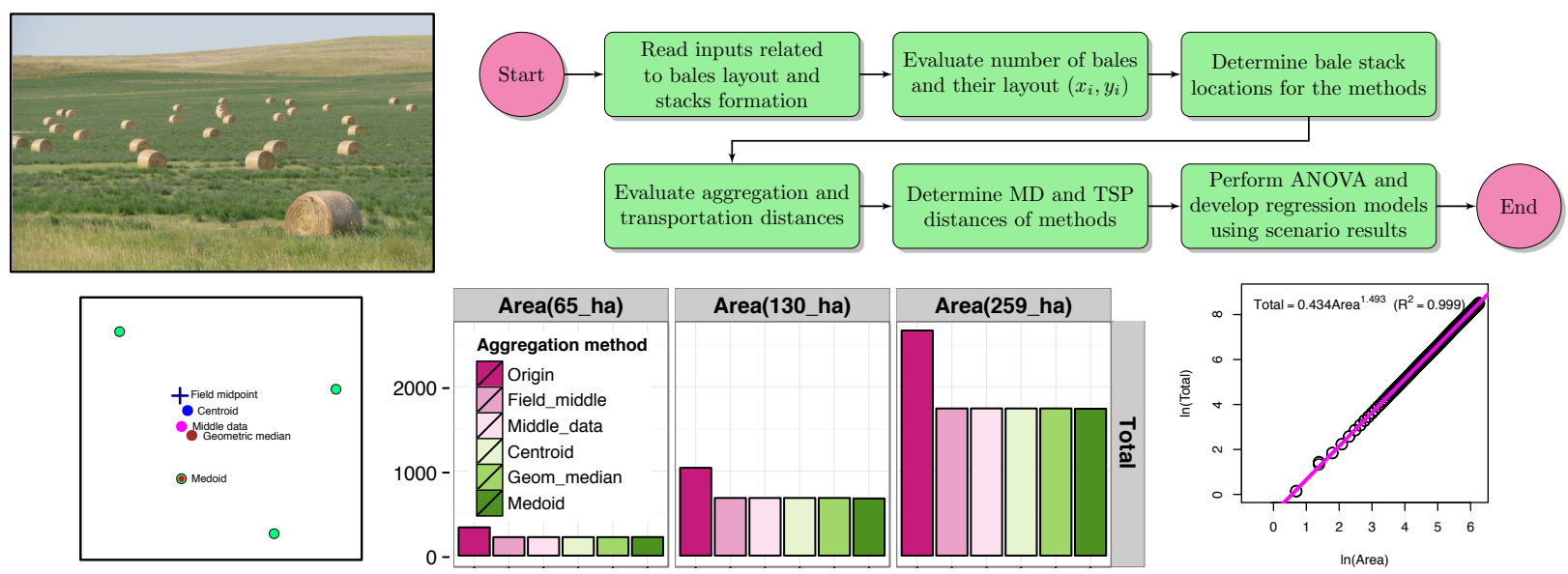